\title{
Identifying Moral Foundations and Disciplinary Frameworks of Engineering Ethics
}

\section{Dr. Jonathan Beever, University of Central Florida}

Jonathan Beever is Assistant Professor of Philosophy and faculty with the Texts \& Technology Ph.D. Program at The University of Central Florida. Dr. Beever holds numerous national level leadership positions and works and publishes at the intersection of environmental ethics and bioethics, focusing on questions of ethics, science, and representation. He teaches a wide variety of undergraduate and graduate courses on related topics.

\section{Dr. Laurie A. Pinkert, University of Central Florida}

Laurie A. Pinkert is an Assistant Professor of Writing and Rhetoric at the University of Central Florida. Her research examines the role of communication practices and writing infrastructures in disciplinary development within fields such as engineering. 
Identifying Moral Foundations and Disciplinary Frameworks of Engineering Ethics

Much, if not most, of engineering ethics has consistently focused on the ways in which individuals make ethical decisions and, in turn, the ways in which engineering ethics educators can cultivate ethical decision making in individual's behaviors. The target of this type of inquiry has been on the explicit outcomes of ethics: increasing reasoning skills, developing ethical motivation, evidencing ethical sensitivity. While this focus has been important for analyzing and shaping the ways that engineers develop, it often ignores the value positions from which individual start in favor of attention to frameworks that can shape continued development.

Recent work coming out of team science research, however, highlights a new direction that is ripe for attention and consideration in engineering ethics: that "members may differ in their values and motivations, shaped by their unique areas of expertise, organizational contexts, or life experiences" [1]. This observation that those working in teams, as engineers often do, need to work across value and motivation differences suggests that cultivating ethical outcomes may not be solely linked to the frameworks that facilitate such outcomes but also connected to the implicit values - the foundations - that shape individuals. In response to this problem, we argue that engineering ethics education ought to work to identify ethical orientations - made up of both moral foundations and ethical frameworks - present in engineering sub-disciplines and determining how these orientations might support (or inhibit) effective decision-making across disciplinary boundaries.

This shift in inquiry pushes our attention beyond the explicit behaviors that demonstrate ethical outcomes to include a more foundational level - the level of implicit values. In this paper we posit a fundamental relation between foundations and frameworks of ethics that has been largely neglected. We argue that looking at implicit or embedded value perspectives is primary to understanding how individuals are oriented to ethical problems, and then how they develop in their thinking about complex ethical problems. We first argue that the prevalent focus on frameworks of ethics targets how individuals reason explicitly about ethical issues, rather than what they value implicitly. We then outline the relevance of examining foundations - describing what ignoring them leaves aside and what focusing on them gains engineering ethics researchers. We hypothesize that keeping the role of foundations distinct from the role of frameworks will result in richer and clearer approaches to engineering ethics pedagogy and assessment. We then describe a promising method for exposing foundations in a way that can be productive at the individual level and may also lead to new knowledge about whether or not foundations operate at other collective levels such as institutional or disciplinary ones. Finally, we discuss further empirical analysis that can evidence the extent to which this method has weight and direction in the context of engineering (sub)disciplines. 
The Prevalent Focus on Frameworks of Ethics

The prevalent focus on frameworks of ethics targets how individuals reason explicitly about ethical issues, rather than what they value implicitly. Of course, researchers have developed a diversity of frameworks for cultivating ethical decision-making and implemented them within and across engineering and STEM disciplines more generally. By frameworks, we mean formalized mechanisms for introducing approaches to framing and analyzing ethical issues often institutionalized in the form of courses, mentorship, workshops, and professionalization seminars. We juxtapose these formalized or instructional experiences within disciplines with the implicit values that individuals bring to the problem with them. Frameworks are as diverse as the engineering programs that seek to implement them; however, we categorize them into two types: those focused on reasoning skill development, and those focused on motivational or behavioral changes. Reasoning frameworks utilize a range of mechanisms including normative theory, step- based decision-making models, professional codes of conduct, and responsible conduct of research infrastructures. Motivational frameworks rely on externalized influences on behavior, including economic structures of reward and penalty, regulatory protocol, punitive academic structures, leadership or character-based models, and sensitivity building exercises.

In each case, several frameworks for cultivating ethical decision-making at the individual level have been developed and implemented within and across engineering and related STEM disciplines. Generally speaking, such frameworks have been viewed and studied widely in the literature. For example, some motivational frameworks have focused on the moral sensitivity of individuals as a necessary condition for ethical decision-making [2], [3], [4], [5], [6]. Other work has focused even more narrowly on the role of normative principles on individual reasoning, like Beever and Brightman's proposal that a reflexive principlism [7] has potential for effectively cultivating ethical decision- making in engineering at that individual level. In current collaborative STEM research, reasoned decision making is one of the key frameworks analyzed [8], [9], [10], [11], [12], [13], [14], despite 2015 evidence from the National Research Council that ethical decision-making has been largely overlooked [15].

This diversity of frameworks is distinct from and, we argue, secondary to how individuals are oriented toward ethics generally. Frameworks emphasize how individuals value, in terms of the practical rational and motivational aspects of decision-making, while foundations of ethics emphasize what individuals value, or how value priorities are structured for each individual. In the context of engineering, you might imagine a scenario where an individual engineer approaches a problem $\mathrm{X}$ with a certain implicit value orientation (call it A). A second engineer approaches that same problem $\mathrm{X}$ with a different value orientation, $\mathrm{B}$. A framework-based approach to engineering ethics might help us understand that these two engineers may make different decisions, but they do not - and cannot - help us understand why they make different decisions. Diverse frameworks of ethics compound the diversity of moral foundations to such an extent that 
the ethicists' failure to make sufficient differentiations among them will lead inevitably to a poor understanding of ethical decision-making.

While frameworks are necessary to do ethical decision-making - in that they help structure thought and procedure toward particular ends - they only help to surface what individuals already value. Frameworks focus on external outcomes or behaviors, and are silent about or fail to have substantial impacts on or shifts in individuals' behavior or understanding. They are merely "poking the bear" (as our Romanian colleague might colloquialize) by stimulating our moral sensibilities but not understanding or identifying them.

The Relevance of Examining Foundations

Identifying and understanding ethical orientations requires the examination of foundations. Focusing on ethical frameworks, whether in terms of reasoning skills, behavioral changes, or decision-making development, tends to emphasize externalized capacities while neglecting questions about constitution; that is, what is it about the individual that orients them to ethical problems and motivates them to develop, change, or act in response to ethical issues? This is the problem of ethical foundations. While this idea has been given a contemporary public face through the work of moral psychologist Jonathan Haidt [16], it has been voiced in parallel through the idea of what philosopher Nancy Tuana has called "intrinsic ethics" [17].

Our individual orientations to the values moral foundations encode are implicit, or "pre-wired," and, on this psychological theory, only recognizable by the active process of making these implicit foundations explicit. The application of Jonathan Haidt's moral foundations theory to political orientations in the United States (i.e., liberals vs. conservatives) began as his making-them-explicit - as examples of the ways in which these value orientations play out, practically in the world. For example, the politically liberal, Haidt evidences, prioritize a care/harm orientation to a greater extent than their conservative counterparts.

The success of MTF theory in describing sociopolitical differences has been proved and refined empirically. For instance, in their 2013 study, Federico et al find that their results "indicate that... while orientations to preferences about equality versus inequality are most closely linked to the individualizing foundations" identified by moral foundations theory, "orientations relevant to social openness versus order are most closely linked to the binding foundations" identified by moral foundations theory [18]. The authors see this result as a refinement of earlier work in which moral foundations theory was evidenced to identify more generally liberal-conservative differences [19]. Another 2016 study actually tested MFT as a theory of political ideology. That study found substantial variability in individual-level moral foundations across time, problematizing its ability to account for changes in political attitudes. The authors hypothesize, among other things, that "any within-individual change in these modules should predict within-individual change in political attitudes and ideologies" [20]. What they hypothesize, more accurately, is a causal relationship 
between moral foundations and political ideology [21] - and, based on the methods of their study, find no statistically significant evidence of such a causal relationship in one particular direction. There's some relationship, but they can't determine which direction it occurs. And this result makes some sense, since MFT's originators conceive of moral foundations as variable across time and context to a greater extent than other personality traits. "This suggests place and context "turn the dials" of moral foundations to a greater extent than is typical for ideology" [22].

Moral foundations theory has also started being used in both constructive and critical ways to examine other social-psychological differences. For instance, a paper [23] on public views of sexual offending looked at the "psychological mechanisms" that underpin demographic correlates about sexual offenders. MFT was proposed as a theory that could be used to test differences. This paper offered an initial theoretical explanation of moral foundations' role in this context, with a call for future empirical work.

This idea, embedded within moral foundations theory, that there are implicit but fundamental structures to the ways we are oriented to particular values is not unique to MFT. This same basic idea has, for instance, been labeled "embedded" or "intrinsic" ethics by philosopher Nancy Tuana in the context of theorizing STEM ethics education [24]. As Tuana sees it, ethics training often overlooks this level or context of ethics, which focuses on "where ethical issues and values choices are embedded within the context of science" [25]. In the context of scientific inquiry, intrinsic ethics is the "identification of values and assumptions that are embedded in the very context of hypothesis development, data gathering and analysis, governing equations, models, strategies for addressing uncertainty, and the like...." [26]. Haidt offers one model of just this sort of identification.

These implicit or embedded value perspectives are primary to a second-level understanding of how individuals are oriented to ethical problems and then how they develop in their thinking about complex ethical problems. In the context of engineering, this is a particularly compelling distinction to make, since the discipline of engineering is constituted by numerous specializations or subdisciplines, and much of the work of engineering is carried out in the context of collaborative, multi-disciplinary teams. That primary line of inquiry, focusing on foundations, can answer questions like, "Are the same value orientations shared between individuals?," "Do individuals within academic and professional disciplines share the same value orientations?," and "Can these similarities and differences be made explicit?" Dependent on answers to questions like these, the second-level work of understanding how team-based or collaborative work functions, how disciplinary enculturation occurs, and how professionalization progresses can be made clearer and more effective. 
In this section we offer an overview of a promising method for exposing individual foundations of ethics and collecting information that would allow engineering ethics scholars and educators to determine whether and to what extend moral foundations are shared across collective groups. Moral psychologist Jonathan Haidt has developed what he has called "moral foundations theory" (MFT) grounded in the idea that we each are pre-wired (neurologically, informed by evolution) with a set of value orientations to problems that are then fine-tuned and organized by lived experience. In this way, MFT follows a form of ethical universalism shared by contemporary bioethical principlism, which argues similarly that the ethical principles of beneficence, nonmaleficence, respect for autonomy, and justice are "hard-wired" or universal across individuals, but are balanced and specified in context and with experience [27]. But whereas bioethical principles are fine-tuned by reason, or intentionally, moral foundations are psychologically implicit and fine-tuned by experience (via cultural context).

MFT outlines a list of five moral foundations, described in terms of their polarities. The care/harm foundation builds on Haidt's understanding of the evolutionary development of mothering, or parenting more broadly. Attention to the suffering of others drives the development of this foundation. Haidt offers two examples meant to demonstrate the implicitness of this foundation: a photo of his own son sleeping between two stuffed toy monkeys, and a photo of a hunter poised to club a baby seal on the ice [28]. He argues that most of his readers will be implicitly drawn to feel positively toward the former and negatively toward the latter; hence, care and harm. The fairness/cheating foundation builds on evolutionary altruism, the idea that we are pre-wired toward generosity toward in-group members both in terms of cooperation and reciprocity. Again, since these are implicit pre-wired norms, our feelings are instructive. Haidt argues, "We feel pleasure, liking, and friendship when people show signs that they can be trusted to reciprocate. We feel anger, contempt, and even sometimes disgust when people try to cheat us or take advantage of us" [29]. Similarly, the loyalty/betrayal foundation is grounded in biological evolution. Human animals (and not exclusively human animals) engage in tribal behaviors, asserting patterns of social organization and coalitions, and engaging in war and in-fighting. This foundation orients us all (again, to varying degrees based on the effects of our experiences on our prioritization of these value foundations) to concerns about betrayal and loyalty. The fourth foundation, on authority/subversion, likewise develops from an argument about our implicit orientations to these concepts. Haidt directs us to consider how we (Americans, in this case) feel when asked by a superior to use their first name rather than their formal titles of Mr., Mrs., Dr., et cetera. Similarly, Haidt suggests we feel uncomfortable when someone with whom we are unfamiliar uses our first name rather than our title. And Haidt reminds us that authority (and its counterpart subversion) hinge on the maintenance of order and justice - it's not just about power but about relationships [30]. Finally, the fifth foundation focuses on sanctity and degradation. Here, Haidt argues that 
the evolutionary drive to avoid "pathogens, parasites, and other threats" led to the development of the moral foundation of sanctity - some (potential edible) things were seen to be off-limits, for the same of our survival. This ethical norm grew beyond food to include cultural differences, too, some of which arise in us feelings of disgust or distain.

This approach to understanding the foundational value orientations that individuals bring to ethical issues has had little reception within engineering. One exception was Harold Walker's essay for the 2016 ASEE Mid-Atlantic Section conference, in which he argues that some of Haidt's "elements of morality" but not others are privileged in "a number of engineering texts" [31]. Thus, this distinction between frameworks and foundations remains grossly understudied in the context of engineering ethics.

Of course, the importing of moral foundations theory into engineering ethics brings with it some compelling critical questions. Thinking back to what we identified above as the lines of inquiry a focus on foundations can bring, what are the implications for engineering if research shows that individuals within a particular engineering sub-discipline share moral foundations in common? Would this mean friction between sub-disciplines? What if no such differences are demonstrated? Does this mean that value orientations are readily overcome by the processes of professionalization and enculturation? What might a shared disciplinary or sub-disciplinary foundation mean for those individuals who seek to enter the field but do not prioritize the same foundation as the discipline does? Are individuals required to refine or reject the discipline's or their individual foundations throughout the process of enculturation? Does this contribute to the persistence of and potential diversity within such fields?

The tools associated with moral foundations theory, including validated survey instruments, can be applied in future work to begin to evidence answers to some of these questions. We hypothesize, for example, that a case study comparing biomedical engineers to electrical engineers would find commonalities between individuals within those sub-disciplines but differences between them. And even if any future empirical results are not this clear cut, engineering ethics researchers will have a richer story to tell nonetheless about how sub-disciplines are co-constituted by/with their members, and how this constitution has implications for team- based, collaborative work.

\section{Future Directions and Potential Empirical Support}

Indeed, such hypotheses demand empirical testing. While moral foundations theory has been applied to political differences, it is only beginning to be discussed in relationship to academic disciplines. For example, Pinkert, Hannah, and Lam posit initial evidence of shared disciplinary foundations outside STEM, through their piloting of MFT survey in a workshop designed for the Association of Teachers of Technical Writing [32] where participants collectively scored harm and fairness more strongly than the other 
foundations, compared to national norms. In alignment with such lines of inquiry and possibility, we posit that moral foundations operate generally as threshold concepts [33], creating the possibility for engaging in a previously inaccessible way of thinking and irreversibly altering ethical thought and practice - in the context of STEM disciplines as much as in the context of political thought. As such, we hypothesize that members of an institution or members of a shared disciplines may share modes of thought and practice, making the process of building shared decision-making frameworks more readily possible for those who share disciplinary and ethical homogeneity than for those who do not.

At the very least, the distinction between frameworks and foundations we have emphasized in this essay identify two components of engineering ethics that are fundamentally related. And while there are various ways that frameworks might be related to foundations - ways to be evidenced empirically in future work we have argued that engineering ethicists cannot sufficiently understand one without understanding the other. Engineers, in all their sub-disciplinary specializations, are challenged by diverse ethical foundations and various types of ethics training; therefore, a better understanding of the foundations and frameworks from which various disciplines draw can enable more effective communication and ethical-decision making across disciplinary boundaries.

This distinction between frameworks and foundations has, we think, larger implications still, specifically implications for why and how engineering students come to be enculturated into the profession or subdisciplinary cultures of their field. Initial studies of enculturation within STEM disciplines indicate that ethical values, societal and professional norms, and ethical decision-making strategies each play a substantial role at all stages of the research process [34], [35], [36], [37]; that is, frameworks and foundations are necessary to the process of enculturation. Yet, the distinction between the two remains unclear. In response, we have argued for the importance of this distinction and identified an important gap in how and by what means values play a role in an individual's disciplinary enculturation. To fill this gap, we have hypothesized that disciplinary enculturation is affected by an individual's own implicit value foundations in relationship to and dialogue with the explicit value frameworks in place within graduate education and professionalization. Future work can evidence that relationship between moral foundations and ethical frameworks, and support more careful analysis of the individual as ethical decision-maker within the complex landscape of engineering ethics.

\section{References}

[1] NAP, Enhancing the Effectiveness of Team Science. National Academies Press. https://doi.org/10.17226/19007, 2015: 30.

[2] M. Bebeau, J. Rest, and C. Yamoor , "Measuring Dental Students' Ethical Sensitivity . "Journal of Dental 
Education 49(4): 225-235, 1985.

[3] J. R. Sparks, Prof essional Ethical Sensitivity: The Case of Mar keting Researchers. Texas Tech University, 1995.

[4] D. Narvaez, "Ethical Sensitivity.” Activity Booklet 1. Retrieved from

http:/ / cee.nd.edu/curriculum/documents/actbklt1.pdf. Accessed 2.15.16, 2001.

[5] H. Clarkeburn, “A Test for Ethical Sensitivity in Science.” Journal of Moral Education 31(4): 339- 453, 2002.

[6] N. Tuana, "An Ethical Leadership Developmental Framework.” In The Handbook of Ethical Educational Leadership, 153-175. Ed. C.M. Branson, S.J. Gross. Hoboken: Taylor and Francis, 2014.

[7] J. Beever and A.O. Brightman, "Reflexive Principlism as an Effective Approach for Developing Ethical Reasoning in Engineering.” Science and Engineering Ethics 22(1): 275-291, 2015.

[8] T.M. Jones, "Ethical Decision Making by Individuals in Organization: An Issue-Contingent Model." The Academy of Management Review 16(2): 366-395, 1991.

[9] H.M. Sharp, "Ethical Decision-Making in Interdisciplinary Team Care." Cleft-Palate-Craniofacial Journal 32(6): 495-499, 1995.

[10] L.K. Trevino, "Ethical Decision Making in Organizations: A Person-Situation Interactionist Model.” The Academy of Management Review 11(3): 601-617, 1996.

[11] A. Botes, "An Integrated Approach to Ethical Decision-Making in the Health Team.” Journal of Advanced Nursing 32(5): 1076-1082, 2000.

[12] B.W. Husted, and D.B. Allen, "Toward a Model of Cross-Cultural Business Ethics: The Impact of Individualism and Collectivism on the Ethical Decision-Making Process." Journal of Business Ethics 82(2): 293-305, 2008.

[13] S.W. DeGrassi, W.B. Morgan, S.S. Walker, Y. Wang, and I. Sabat, "Ethical Decision-Making: Group Diversity Holds the Key.” Journal of Leadership, Accountability and Ethics 9(6): 51-65, 2012.

[14] J.L. Craft, “A Review of the Empirical Ethical Decision-Making Literature: 2004-2011.”Journal of Business Ethics 117: 221-259, 2013.

[15] National Research Council (NRC). "Enhancing the Effectiveness of Team Science." National Academies Press, 2015.

[16] J. Haidt. The Righteous Mind. New York: Vintage, 2012.

[17] N. Tuana, "Leading with Ethics, Aiming for Policy: New Opportunities for Philosophy of Science." Synthese 177:471-492, 2010.

[18] C.M. Federico, C.R. Weber, D. Ergun, and C. Hunt. "Mapping the Connections Between Politics and Morality: The Multiple Sociopolitical Orientations Involved in Moral Intuition.” Political Psychology 34(4): 607, 2013.

[19] J. Graham, J. Haidt, and B. Nosek. "Liberals and Conservatives Use Different Sets of Moral Foundations.” Journal of Personality and Social Psychology 96: 1029-1046, 2009.

[20] K.B. Smith, J.R. Alford, J.R. Hibbing, N.G. Martin, P.K. Hatemi. "Intuitive Ethics and Political Orientations: Testing Moral Foundations as a Theory of Political Ideology." American Journal of Political Science 61(2): 425, 2016.

[21] Ibid 430.

[22] Smith et al 2016: 435.

[23] C.A. Harper and A.J. Harris. "Applying Moral Foundations Theory to Understanding Public Views of Sexual Offending.” Journal of Sexual Aggression 23(3): 111-123, 2017. 
[24] N. Tuana, "Leading with Ethics, Aiming for Policy: New Opportunities for Philosophy of Science." Synthese 177: 479, 2010.

[25] ibid.

[26] N. Tuana, "Leading with Ethics, Aiming for Policy: New Opportunities for Philosophy of Science." Synthese 177: 481, 2010.

[27] T.L. Beauchamp, Principles of Biomedical Ethics: $6^{\text {th }}$ Edition. New York: Oxford University Press, 2010. [28] J. Haidt. The Righteous Mind. New York: Vintage, 2012: 155.

[29] ibid: 158. [30] J. Haidt. The Righteous Mind. New York: Vintage, 2012: 167.

[31] H.W. Walker, "Moral Foundations of the Engineering Profession." 2016 ASEE Mid-Atlantic Section Conference. American Society for Engineering Education, 2016.

[32] L.A. Pinkert, M.A. Hannah, and C. Lam. What are the moral foundations of technical communication? Association of Teachers of Technical Writing, Kansas City, KS, 2018.

[33] J.H.F. Meyer and R. Land, (eds.), Overcoming Barriers to Student Understanding: threshold concepts and troublesome knowledge, London and New York: Routledge, 2006.

[34] N. Tuana, "Embedding Philosophers in the Practices of Science: Bringing Humanities to the Sciences." Synthese 190(11): 1955-1973, 2013.

[35] A.M. Petersen, I. Pavlidis, and I. Semenderferi, "A Quantitative Perspective on Ethics in Large Team Science.” Science and Engineering Ethics 20(4): 923-945, 2014.

[36] D.J. Hicks, “A New Direction for Science and Values.” Synthese 191: 3271-3295, 2014.

[37] National Academy of Engineering (NAE), NAE Annual Report 2014: Engineering the Future, 2014. 